\title{
AMOEBIC LIVER ABSCESS IN AFRICAN CHILDREN
}

BY

\author{
JOAN SCRAGG
}

From the Department of Paediatrics, University of Natal, the King Edward VIII Hospital and the Amoebiasis Research Unit*, Durban, South Africa

(RECEIVED FOR PUBLICATION JUNE 13, 1959)

Amoebiasis is common among Africans in Durban, where this hospital alone handles over 2,500 patients each year. Children share in this high incidence of the disease. Many cases are severe and liver abscess is frequently seen.

The purpose of this paper is to compare and contrast the features of amoebic liver abscess in children with those in adults and to discuss clinical diagnosis.

\section{Material}

This consists of a series of 53 cases of amoebic liver abscess admitted to the Paediatric Department during a period of seven years from November, 1951. All were proved by demonstration of pus either by aspiration or at necropsy.

Age Incidence. The age distribution is shown in Fig. 1. The youngest was 8 weeks and the oldest 5 years. Seventeen were under 1 year, 10 being less than 6 months old.

Senecal, Larivière, Dupin and Trenou (1957), in reporting four cases of amoebic liver abscess in children, state that Lestrade and Guérineau had found that up to 1956 the world literature contained only 47 reported cases of amoebic liver abscess in children. Since then Torroella, Lopez and Villareal (1956) have described 14 cases in children under 6 years in Mexico.

Although this condition is uncommon in children elsewhere, it is not infrequently seen in African children in Durban.

Sex Distribution. Thirty-two of the 53 cases were males. Torroella et al. (1956) described 14 cases in children, of whom 5 were males. It appears that male predominance is less in children than in adults.

* The Amoebiasis Research Unit is sponsored by the following bodies: the South African Council for Scientific and Industrial Research, the Natal Provincial Administration, the University of Natal, and the United States Public Health Service (Grant E-1592).

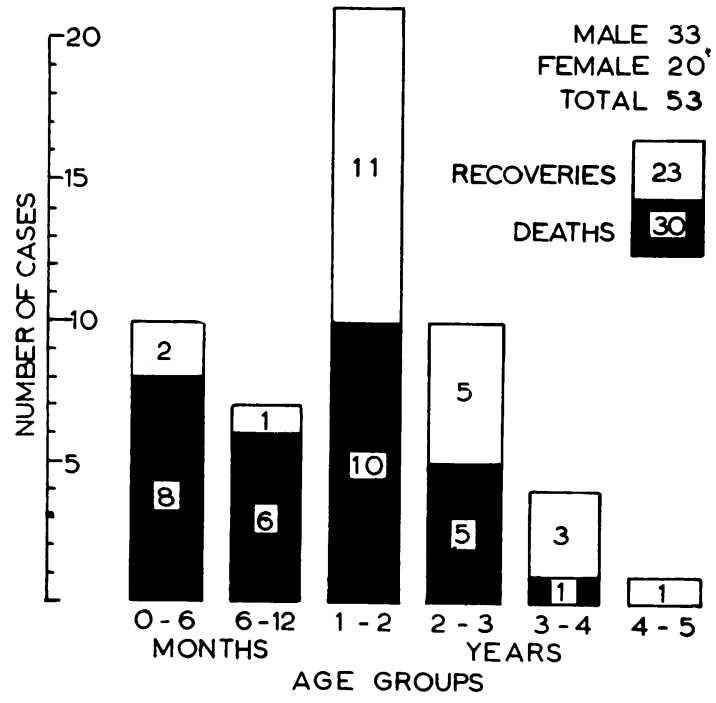

Fig. 1.-Amoebic liver abscess in children. Age incidence and outcome of 53 cases.

Location of Abscesses. The location of abscesses clinically and at necropsy was as follows:

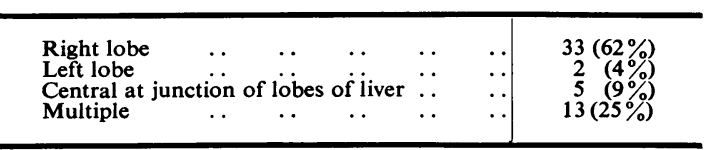

Abscesses are said to be characteristically single and to occur most often in the right lobe. In this series $75 \%$ were single and $25 \%$ multiple (Fig. 2). These figures show that the distribution of single abscesses is similar to that reported elsewhere. It seems that multiple abscesses are commoner in Durban African children than is usually the case, 
but this may be due to the high proportion of necropsies.
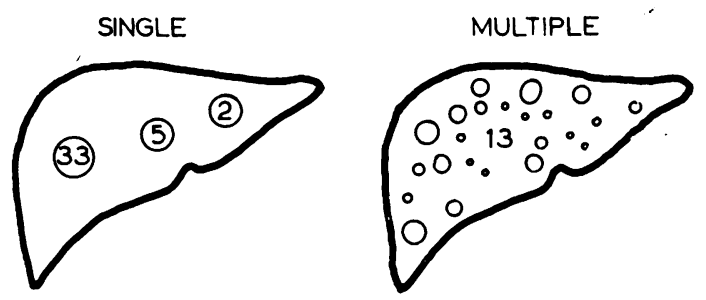

FIG. 2.-Location of amoebic liver abscesses in 53 cases.

Fever. This was present in all cases (Fig. 3). The temperature usually fluctuated between 102 and $103^{\circ} \mathrm{F}$. until appropriate therapy was begun. In adults fever is not a constant manifestation of liver abscess (Wilmot, 1949; Lamont and Pooler, 1958). In children, however, it is an important and striking feature. was observed in 34 cases, and between 30,000 and 43,000 W.B.C.s per c.mm. in six others. Two fatal cases with extremely high counts were found to have single hepatic lesions at autopsy. Three with very high counts recovered and the two lowest counts of 8,000 and 9,000 occurred in children who at autopsy had multiple lesions. These findings do not confirm the opinion that a pronounced leucocytosis indicates multiple abscesses with a bad prognosis (Rogers, 1922).

My findings show that in children the white cell count is more often raised and the elevation is greater than in adults, in whom leucocytosis is present in only $70-80 \%$ (Wilmot, 1949; Lamont and Pooler, 1958).

In these children the duration of the history bore no relationship to the level of the white cell count, unlike the findings of Lamont and Pooler (1958).

A normocytic normochromic anaemia was present in 38 cases, the haemoglobin being $7.6 \mathrm{~g} . / 100 \mathrm{ml}$. (range 4.8 to $10.0 \mathrm{~g} . / 100 \mathrm{ml}$.). Anaemia is an important feature of the disease in children and

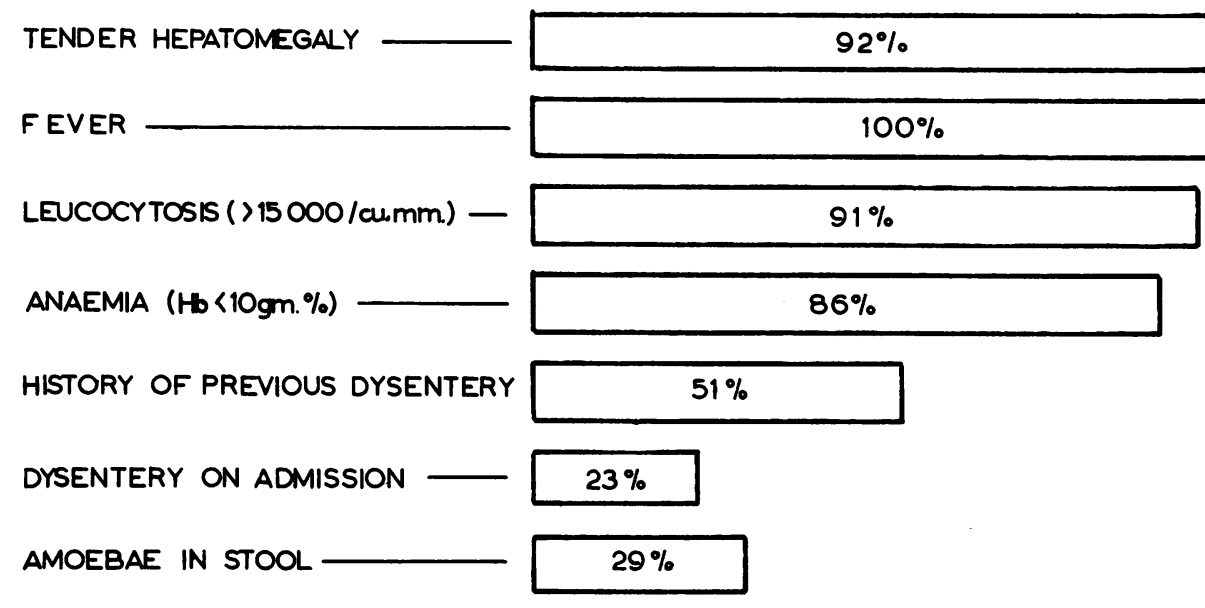

FIG. 3.-Incidence of common clinical findings in 53 cases of amoebic liver abscess.

Tender Hepatomegaly. This was present in all but four cases. It is unusual for the liver not to be enlarged to at least three fingers' breadth below the costal margin. Intercostal tenderness may be difficult to elicit in infants but direct palpation of the liver is usually exquisitely painful. A palpable mass was present in 40 .

Haematological Findings. Blood examination was done in 44 cases. The white blood cell count was raised in $40(91 \%)$. In the remaining four it ranged from 8,000 to 11,000 W.B.C.s per c.mm. Leucocytosis between 15,000 and 29,000 W.B.C.s per c.mm. rapidly improves with treatment of the primary disease.

Radiological Findings. Radiological examination of the chest was done in 35 cases; 11 (31\%) showed elevation of the diaphragm, seven of these having associated pulmonary changes. Figs. $4 a$ and $b$ and $5 \mathrm{a}$ and $\mathrm{b}$ show the radiological changes in two cases. It seems that radiology is less often helpful in children than in adults, among whom the majority exhibit diaphragmatic elevation (Ochsner and DeBakey, 1943; Wilmot, 1949; Lamont and Pooler, 1958). 

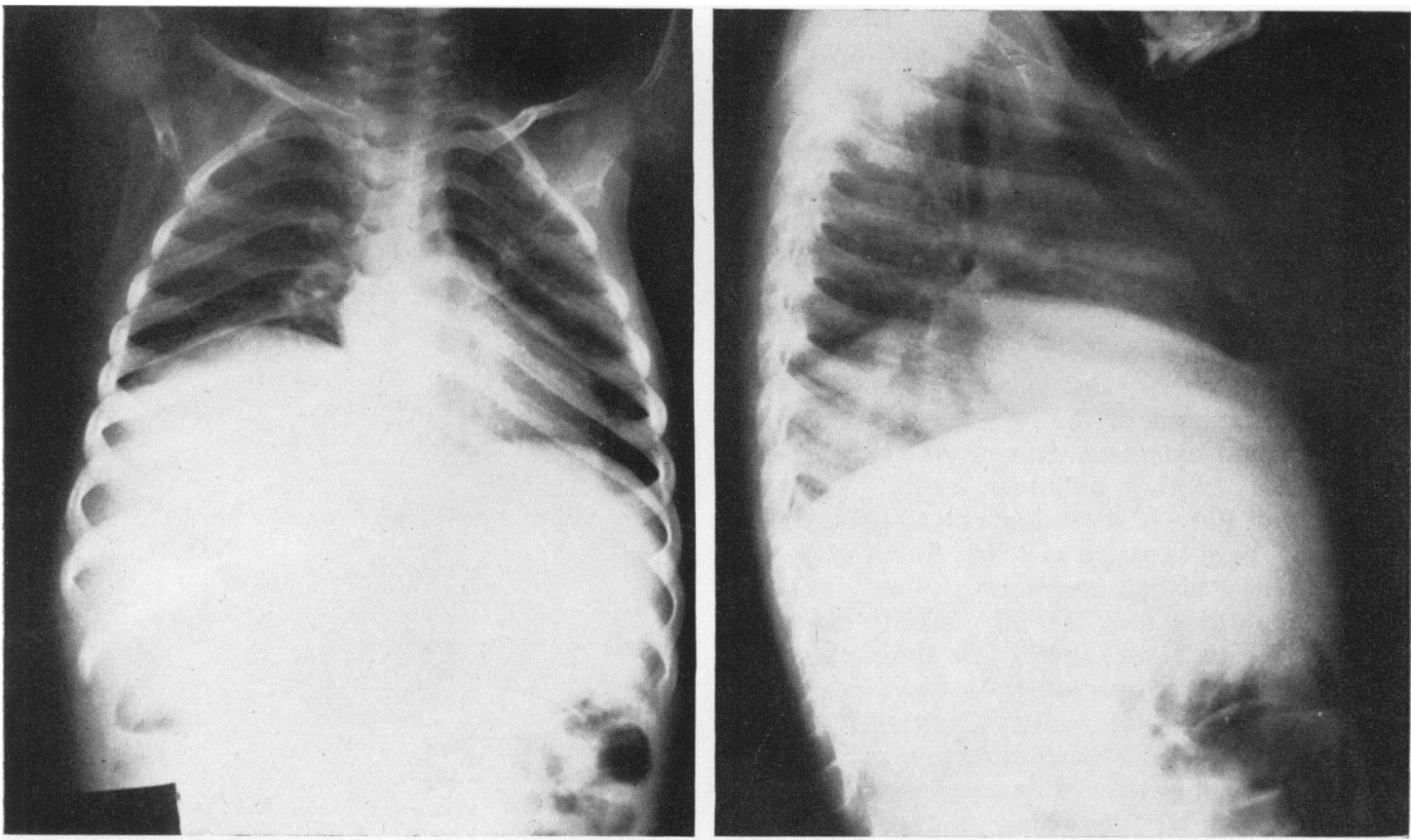

FIG. 4a.

FIG. 4b.

Fig. 4 (a and b).-Radiographs of chest showing marked elevation of right dome of diaphragm before aspiration of large liver abscess (total of $926 \mathrm{ml}$. of pus removed).
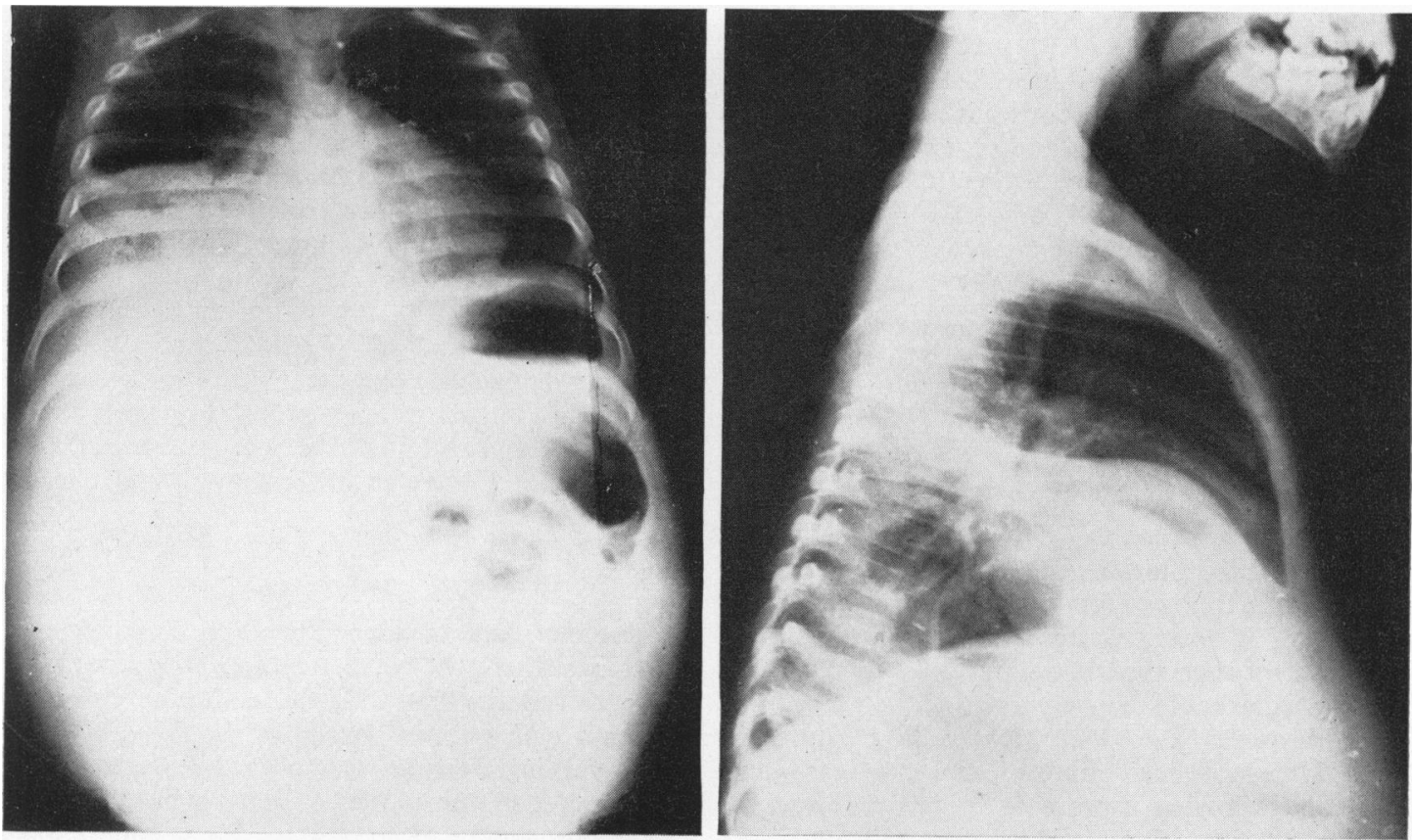

FIG. 5a

FIG. 5b.

FIG. 5.-(a) Radiograph showing marked elevation of right dome of diaphragm; (b) after aspiration of $80 \mathrm{ml}$. of pus from liver; air can be seen in abscess cavity. 
Dysentery or History of Dysentery. Twelve (23\%) of the children had dysentery on admission and a past history of dysentery was obtained in a further $27(51 \%)$. Thus $73 \%$ had antecedent or concomitant dysentery, which is similar to the findings in adults.

The absence of amoebae in the stools by no means excludes the diagnosis of amoebiasis, amoebae being found in only $13(29 \%)$ of the 45 in whom stools were examined. Of seven who died before stool examination, three were found to have no bowel lesion at necropsy. In 13 necropsies in which amoebic ulceration of the bowel was found (eight of whom had extensive ulceration) amoebae were found before death in only two.

Nature of Pus. Classical 'anchovy-coloured' pus should not be anticipated as it was usually grey-green or grey-yellow at first aspiration and only at subsequent aspirations took on the pink or red-brown colour. Roach (1958) found that the abscess contents were yellow in over $90 \%$ of subjects at necropsy and concluded that 'only rarely at necropsy does the liver abscess contain the "anchovy-type" material considered by many to be characteristic'.

Opinions differ regarding the incidence of amoebae in the abscess contents. DeBakey and Ochsner (1951) found amoebae in $26 \%$ of 263 patients. In my series amoebae were found in the pus in eight $(20 \%)$ of 40 cases aspirated and at necropsy in $13(62 \%)$ of 21 cases. With recently improved technique, the Amoebiasis Research Unit, Durban, in a series of 71 consecutive liver abscesses in adults, have observed and/or isolated amoebae from $57(80 \%)$ cases (Maddison, 1959). In future, therefore, we may find amoebae in aspiration specimens with greater frequency.

The pus was characteristically bacteriologically sterile in $36(90 \%)$ of the 40 cases aspirated. In four bacteria were isolated from the first aspirate, but in no case did secondary infection occur as a result of aspiration.

\section{Complications}

Rupture of Abscess. This occurred in five patients (three fatal). In one, intrapulmonary rupture was followed by clinical improvement and recovery. In another, after two aspirations, rupture occurred through the abdominal wall. This infant made a remarkable recovery as he seemed moribund on admission. Two died shortly after admission from intraperitoneal rupture, and one case died suddenly following rupture of the abscess into the pericardium and pleural cavity.

Brain Abscess. This rare complication was found at necropsy in an infant aged 5 months who had a massive abscess in the right hepatic lobe and multiple small abscesses in the left lobe. Amoebae were found in the brain abscess which had caused quite extensive cerebral softening.

Jaundice. Lamont and Pooler (1958) found jaundice in six of their $\mathbf{1 6}$ fatal cases. In my series it occurred in only one case, autopsy revealing two large abscesses producing mechanical obstruction to the biliary system (Fig. 6).

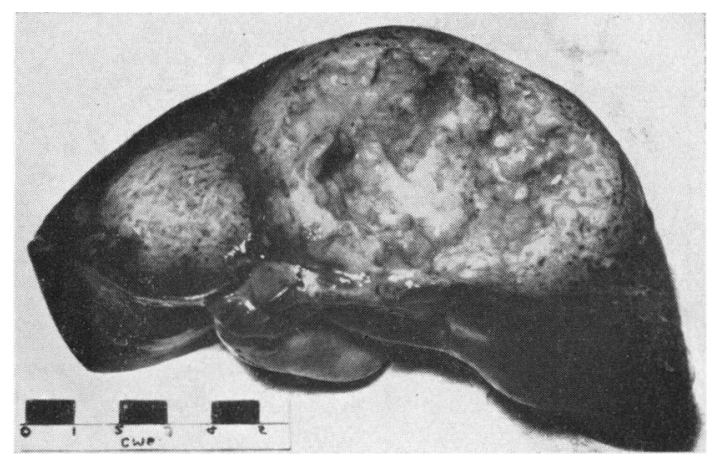

Fig. 6.-Necropsy photograph of liver from infant aged 4 months. Two large abscesses produced mechanical obstruction of biliary system with large mucocoele of gall bladder.

\section{Mortality}

There were 30 deaths, i.e. a mortality rate of $57 \%$. Only two infants, aged 5 months and 7 months, recovered out of the 17 cases under 1 year of age.

The mortality rate in children cannot be assessed since no large series has been reported. In a study of 77 consecutive African patients with liver abscess Wilmot (1949) found a mortality rate of $11 \cdot 7 \%$. DeBakey and Ochsner (1951) reported an overall mortality of $22.2 \%$, the mortality in their series being $100 \%$ in multiple abscesses but only $11 \%$ in those with single lesions. Multiple lesions undoubtedly worsen prognosis for they were present in 12 of the 21 children in whom autopsies were performed. Twelve cases were moribund and died soon after admission.

\section{Treatment}

Specific Anti-amoebic Therapy. Excluding the six cases where the correct diagnosis was not made, all received emetine. To those who survived long enough emetine was given for 10 days, the daily dose varying from gr. 1/8 to gr. $1 / 4$, depending on the weight of the patient. Ten received a further seven-day course of emetine. Chloroquine diphosphate was used in an initial dose of $0.5 \mathrm{~g}$., followed by $0.25 \mathrm{~g}$. daily for 15 to 21 days. As chloroquine 
therapy alone is followed by a significant relapse rate (Harinasuta, 1951; Wilmot, Powell and Adams, 1958), a combination of emetine and chloroquine may be the best form of treatment. In addition tetracycline or its derivatives and diiodo-hydroxyquinoline were given when dysentery was present. Antibiotics are of no value in the treatment of liver abscess (Wilmot, Armstrong and Elsdon-Dew, 1952; Wilmott, Powell and Elsdon-Dew, 1958; Powell, Wilmot and Elsdon-Dew, 1959). Penicillin was usually employed while aspiration was being carried out as a precaution against secondary infection.

Supportive Measures. Intravenous fluids and blood transfusions were used when indicated. The maintenance of hydration and electrolyte balance is of paramount importance when serious dysentery is present.

Aspiration. This was done in 40 cases: 12 were aspirated once only, 18 on two to four occasions, and seven on five to seven occasions; three required 12,13 and 17 aspirations respectively. From the latter case a total of $1,688 \mathrm{ml}$. of sterile pus was removed.

Surgical Drainage. One 5-month-old infant was treated by surgical drainage with good result. A further infant, after seven aspirations, developed a midline sinus and a residual small abscess was evacuated surgically. Rapid and complete cure followed. The last case in this series was immediately submitted for surgical drainage when bacteria were isolated from the first aspirate and cure followed.

\section{Discussion}

In African children in Durban amoebic liver abscess is commoner than elsewhere and for this reason an acute awareness of the condition in childhood is necessary. This condition should always be kept in mind in the differential diagnosis of hepatomegaly, especially tender hepatomegaly, even in the absence of dysentery or a history of antecedent dysentery. The difficulty in determining in a small crying infant whether hepatic tenderness exists is freely admitted. Another feature occasionally making diagnosis difficult is abdominal distension. However, exploratory transcostal needling would appear justified if amoebic liver abscess is suspected, as early diagnosis is one of the most important factors in lowering the attendant high mortality.

The clinical manifestations of amoebic liver abscess in children are similar to those in the adult, except that fever is a more frequent finding. Failure of response to therapy shown by a continuing high fever and increasing anaemia in children with dysentery or a history thereof should suggest the possible presence of an hepatic complication. However, concomitant or antecedent dysentery can be expected in only about two-thirds of cases. With adequate treatment of amoebic dysentery there is usually improvement of the general condition of the child within about five days. Haematological changes, especially anaemia and leucocytosis, are of value in making a diagnosis. As in the adult, while radiological changes when present assist the diagnosis, their absence does not preclude it.

Most workers state that conservative treatment with amoebicidal drugs and closed drainage by repeated aspiration is best except where secondary infection is present. DeBakey and Ochsner (1951) showed a striking difference in mortality with conservative therapy consisting of emetine with or without aspiration compared with open operation. They advocate open drainage immediately if on first aspiration the abscess is secondarily infected.

Wilmot (1958) considers that the main indications for open drainage are:

(1) Failure to aspirate pus from patients with suspected liver abscess whose condition is not responding to emetine and/or chloroquine.

(2) Secondarily infected abscesses which do not respond to aspiration and local and systemic antibiotics.

(3) In some cases after rupture has occurred, in order to drain the pus from other loci.

(4) Cases not improving despite repeated aspiration and specific therapy.

In view of the high mortality rate, in retrospect it might have been advisable to undertake surgical drainage in those who required numerous aspirations. In future more thought should be given to those indications and selected cases should be submitted to surgery. Not all cases of amoebic liver abscess require aspiration on specific antiamoebic treatment. During the period under discussion there were an additional 14 cases of undoubted amoebic liver abscess, but as confirmatory aspiration was not carried out these cases have been excluded from this series.

The management and treatment of amoebic liver abscess in children is basically the same as that advocated for adults.

\section{Summary}

Cases of amoebic liver abscess occurring in 53 African children are reported.

The importance of awareness of the condition and early diagnosis is stressed.

The condition can occur at any age, the youngest case in this series being 8 weeks. 
There is not the distinct male predominance that is noted in the adult.

The abscesses are frequently multiple in children.

The important clinical features and difficulties in diagnosis in childhood are discussed.

The mortality is high (in this series about $57 \%$ ) and only by early diagnosis may complications be prevented.

I wish to record my thanks to Dr. H. L. Wallace, Head of the Department of Paediatrics, University of Natal, to Dr. Pauline Klenerman, in whose wards these cases were treated, and to Dr. S. Disler, Medical Superintendent of King Edward VIII Hospital, Durban, for facilities. I am especially indebted to Dr. R. ElsdonDew, Dr. A. J. Wilmot, Dr. S. J. Powell and Dr. N. Lamont for much valuable criticism and advice. Finally, I wish to record my thanks to Miss A. Killerby for the photographs and to the staff of the Amoebiasis Research Unit for access to the literature.

\section{REFERENCES}

DeBakey, M. E. and Ochsner, A. (1951). Hepatic amebiasis; A 20 year experience and analysis of 263 cases. Int. Abstr. Surg., 92, 209.
Elsdon-Dew, R., Armstrong, T. G. and Wilmot, A. J. (1952). Antibiotics and amoebic dysentery. Lancet, $2,104$.

Harinasuta, C. (1951). A comparison of chloroquine and emetine in the treatment of amoebic liver abscess. Indian med. Gaz., 86, 137.

Lamont, N. McE. and Pooler, N. R. (1958). Hepatic amoebiasis. A study of 250 cases. Quart. J. Med., 27, 389.

Lestrade, P. and Guérineau, P. (1956). L'hépatite amibienne du jeune enfant. Arch. franc. Pédiat., 13, 728.

Maddison, S. E. (1959). Personal communication.

Ochsner, A. and DeBakey, M. (1943). Amebic hepatitis and hepatic abscess. An analysis of 181 cases with review of the literature. Surgery, 13, 460, 612.

Powell, S. J., Wilmot, A. J. and Elsdon-Dew, R. (1959). Hepatic amoebiasis. Trans, roy. Soc. trop. Med. Hyg., 53, 190.

Roach, G. G. (1958). The pathology of amoebiasis: Proc. 6th Int. Congresses on Tropical Medicine and Malaria. In the press.

Rogers, L. (1922). Lettsomian Lectures. Lecture No. 111. The prevention of amoebic liver abscess and the recent reduction in its prevalence and mortality. Lancet, 1, 677.

Senecal, J., Larivière, M., Dupin, H. and Trenou, R. (1957). Quelques aspects des abcès amibiens du foie chez le nourrisson ques aspects des abces amibiens du foie chez

Torroella, J. M., Lopez, T. G. and Villareal, R. (1956). Consideraciones sobre el abscesso hepático amibiano en los niños. Bol. méd. Hosp. infant. Mex., 13, 1023.

Wilmot, A. J. (1949). Clinical Manifestations of Amoebiasis in the Bantu. D.M. Thesis, Oxford University. (1958). Personal communication.

- Armstrong, T. G. and Elsdon-Dew, R. (1952). Aureomycin in amebic liver abscess. Amer. J. trop. Med. Hyg., 1, 429.

-, Powell, S. J. and Adams, E. B. (1958). The comparative value of emetine and chloroquine in amebic liver abscess. Ibid., 7, 197.

liver abscess. Ibid., 7, 656 . 